\title{
MODERN STATE AND CHALLENGES FOR DEVELOPMENT OF LASER AND HYBRID SURFACING TECHNOLOGIES (Review)
}

\author{
V.Yu. KHASKIN, V.D. SHELYAGIN and A.V. BERNATSKY \\ E.O. Paton Electric Welding Institute, NASU \\ 11 Bozhenko Str., 03680, Kiev, Ukraine. E-mail: office@paton.kiev.ua
}

\begin{abstract}
The paper deals with development of the processes of laser and combined (for instance, laser-plasma) surfacing. It is shown that in these processes feeding the surfacing material (mainly, in the form of powder, less often - as wire) into the zone of impact of laser radiation focused into a spot of 1-5 mm diameter results in formation of a deposited layer of a certain height with the specified physico-chemical characteristics on the treated surface. The considered processes have a number of advantages and disadvantages. The advantages include: possibility of deposition of layers of $0.1-3.0 \mathrm{~mm}$ height with specified properties; considerable weakening of the effect of redistribution of components from base material into the deposited layer, promoting an increase of the accuracy of forecasting the results and making the deposited layer properties as close as possible to initial properties of the material being surfaced; producing equiaxed fine-crystalline (highly-dispersed) structures of the deposited metal and small (up to 0.1-0.5 mm) heataffected zone; minimizing the allowance for finish machining to values of $0.3-0.5 \mathrm{~mm}$ to the side due to low roughness (up to $R a 200-300 \mu \mathrm{m}$ ) of the deposited surfaces. The disadvantages include: presence of transverse initial cold microcracks in the deposited layers, appearance of which is the result of relaxation of high internal tensile stresses; possibility of formation of both internal and external pores associated with non-metallic inclusions and residual humidity of the surfacing powder, as well as presence of treated surface contamination; relatively high cost of the process associated with comparatively high cost of laser equipment. It is shown that the main tendencies in development of laser surfacing technology in industrialized countries are as follows: producing corrosion- and wear-resistant coatings with improved physico-mechanical properties; synthesis of 3D objects; producing thin deposited layers with special properties. The prospects for further development of laser and laser-plasma (laser-arc) surfacing processes are associated with the ability to eliminate the drawbacks inherent to each of the components separately, due to interaction of these components. 16 Ref., 3 Figures.
\end{abstract}

$\boldsymbol{K} \boldsymbol{e} \boldsymbol{y} \boldsymbol{w} \boldsymbol{o} \boldsymbol{r} \boldsymbol{d} \boldsymbol{s}:$ laser technologies, hybrid and combined processes, commercial application, equipment, materials, prospects

Laser surfacing as a method of coating deposition, appeared at the end of $1970 \mathrm{~s}-$ beginning of 1980s. In the case of surfacing, feeding of surfacing material (predominantly in the form of powder, more seldom - as wire) into the zone of impact of laser beam focused into a 1-5 mm diameter spot on the surface being treated results in deposition of a coating of a certain height with specified physico-chemical properties (Figure 1) [1, 2 ]. Variants of laser surfacing over layers of surfacing material applied onto the surface before the process are also possible. These layers are applied by thermal spraying or as a mixture, consisting of surfacing powder with binder, and then they are remelted by laser radiation. Surfacing with pre-spraying of the layers is usually called laser remelting. The produced coating is bonded to the base material through a transition layer of comparatively small size (usually, from 5-10 up to $50-200 \mu \mathrm{m}$ ). Strength of coating adhesion to the base metal is quite high and is close to the strength values of the latter.

One of the most important moments in surfacing technology is the method of feeding the surfacing material to the substrate. Studying the technologies of laser welding and surfacing showed that while the processes with wire feeding realize the advantage of treatment performance practically in any position in space, the advantage of powder materials consists in more effective absorption of laser radiation [3]. Downhand surfacing can be performed by preliminary spreading of powder over the surface being treated. Application of powder materials in other positions in space usually requires preliminary application of coatings by such methods as flame spraying, plasma spraying or furnace drying of 

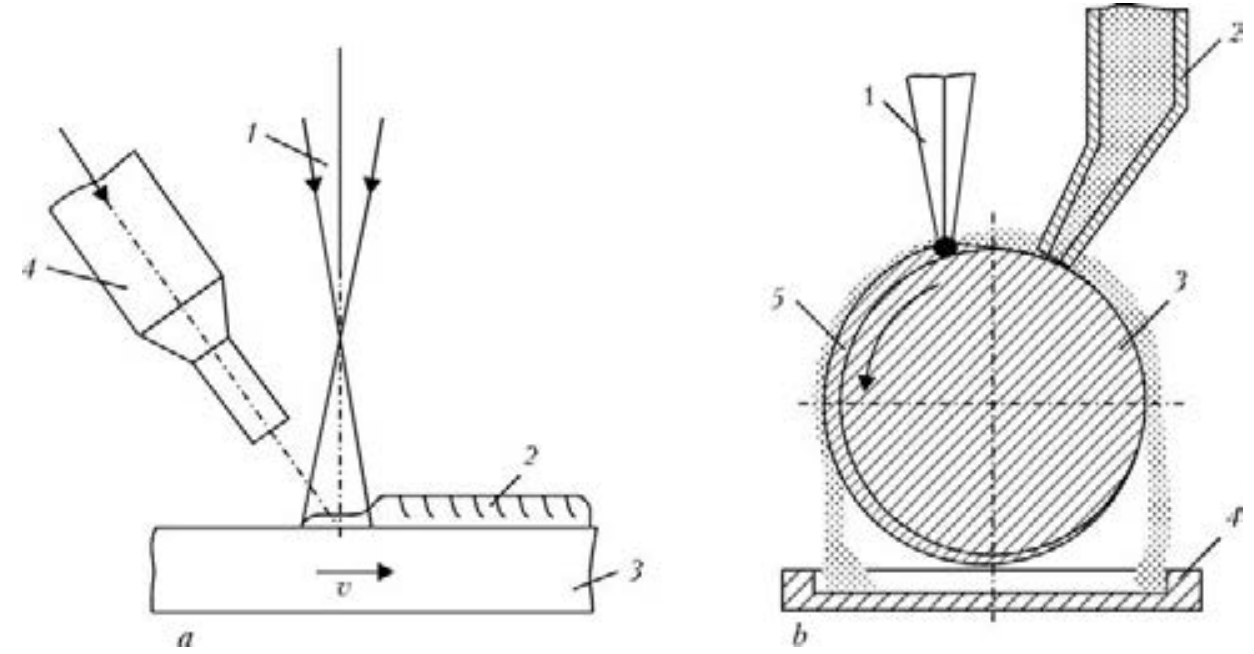

Figure 1. Schematic of processes of laser surfacing of parts of arbitrary geometry $(a): 1$ - laser radiation; $2-$ deposited bead; 3 - moving sample; 4 - nozzle for feeding the shielding gas and filler powder [1], and cylindrical parts $(b)$ : 1 - laser radiation; 2 - feeding tube of powder metering device; 3 - surfaced sample; 4 - nonused powder tray; 5 - deposited metal [2]

coating paste. If the powder cannot be distributed over the surface in advance, it is fed by special metering devices. At present, laser surfacing method became the most widely accepted, which uses filler powder materials, fed directly into the zone of laser radiation impact using special powder metering devices of various designs [4].

Advantages of laser surfacing include [1]: possibility of applying layers of $0.1-3.0 \mathrm{~mm}$ height with specified properties; considerable weakening of the effect of redistribution of components from base material into the deposited layer, promoting an improvement of the accuracy of forecasting the results and achieving deposited layer properties maximum close to those of the surfaced material; producing equiaxed fine-crystalline (highly-dispersed) structures of the deposited metal and small (up to $0.1-0.5 \mathrm{~mm}$ ) HAZ; minimizing the allowance for finish machining up to values of about $0.3-0.5 \mathrm{~mm}$ to the side due to small roughness (up to $R a 200-300 \mu \mathrm{m}$ ) of the deposited metal surfaces. Alongside the abovementioned, laser surfacing advantages further include also those of heat treatment and alloying, associated with the features of laser radiation as a heat source.

The disadvantages of laser surfacing are as follows: presence of transverse cold microcracks in the deposited layers, formation of which is the result of relaxation of high internal tensile stresses [5]; possibility of formation of both the internal and external pores, associated with nonmetallic inclusions and residual humidity of the surfacing powder, as well as contamination of the material being surfaced; relatively high cost of the process, related to comparatively high cost of laser equipment [1]. Controlling, reduction and complete elimination of cracking in laser surfacing was studied at some time by many authors (for instance, [1, 5]). Comparatively recently, Ukrainian authors suggested a mathematical model of this phenomenon, which allowed correlating the distance between the cracks with mechanical properties of the coatings and their thicknesses [6]. It follows from the above-said that methods, which allow lowering residual thermal stresses in the deposited layers in combination with thorough preparation of surfacing powders and treated surface, can be regarded as promising directions of eliminating the process disadvantages. Such methods include, in particular, changing the welding thermal cycle due to application of an additional heat source (for instance, a combination of the impact of laser radiation with that of a plasma jet).

Laser surfacing is used to produce wear- and corrosion-resistant fine-crystalline, amorphized and amorphous coatings from a rather wide material range. However, in the first half of the 1980s laser surfacing has found wider application as the process of reconditioning worn parts of equipment, exposed to sliding friction, shock loads, abrasive wear, etc. [1]. And even now reconditioning laser surfacing is still urgent even in industrialized countries - it is applied for repair of expensive products, at restoration of comparatively small defective areas with high thermal locality [7]. For instance, such technologies are widely applied in processes of reconditioning turbine blades of aircraft engines, supports of shafts, moulds and other expensive products of complex profile [7-9].

Beginning from the start of the XXI century, hybrid and combined technologies more and more 

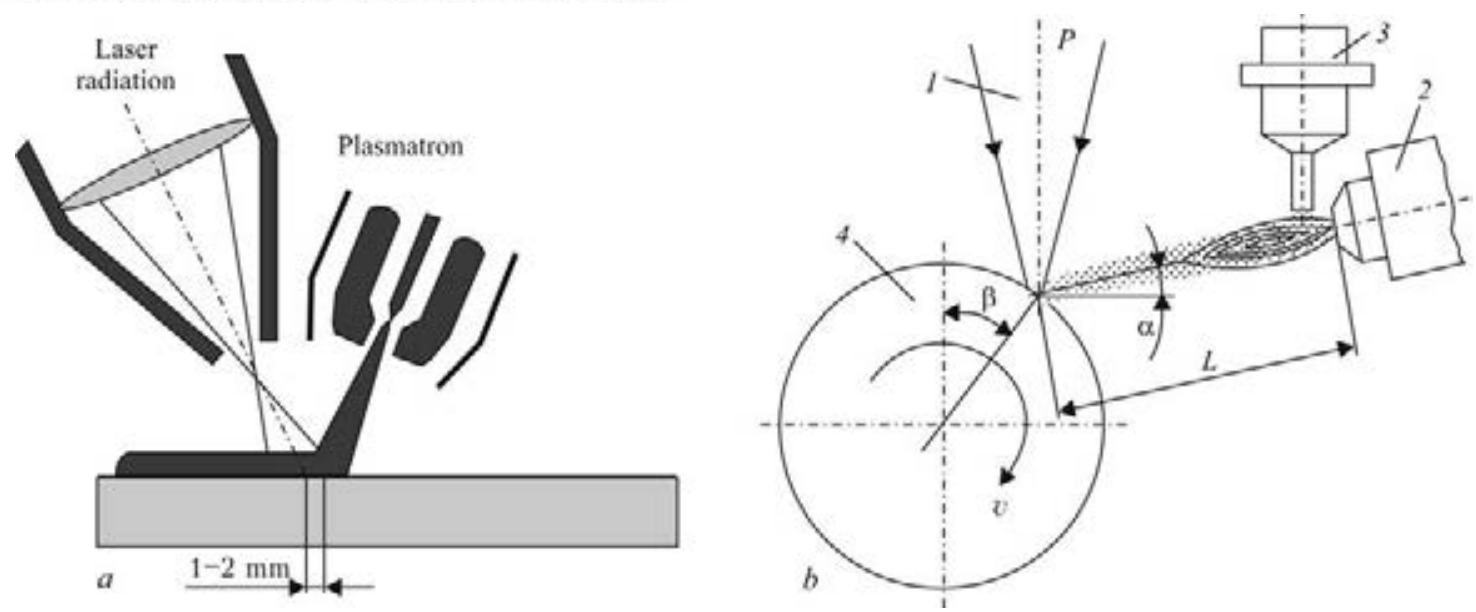

Figure 2. Schematic of processes of powder laser-plasma surfacing using direct- $(a)[10]$ and indirect-action plasmatron $(b): 1$ - radiation; 2 - plasmatron; 3 - powder metering device; 4 - sample; $L, \alpha, \beta$ - surfacing distance and angles [11]

often replace laser technologies. These include laser-plasma processes, which use the simultaneous action of arc plasma and laser energy source. Investigations conducted at the E.O. Paton Electric Welding Institute of the processes of interaction of focused $\mathrm{CO}_{2}$-laser radiation with electric arc column plasma showed that such a system can develop a special type of gas discharge combined laser-arc one [10]. Its properties differ both from those of the electric arc, and from properties of optical discharge maintained by laser radiation. Ability of the combined discharge to generate high-temperature plasma with a high degree of non-equilibrium even at atmospheric

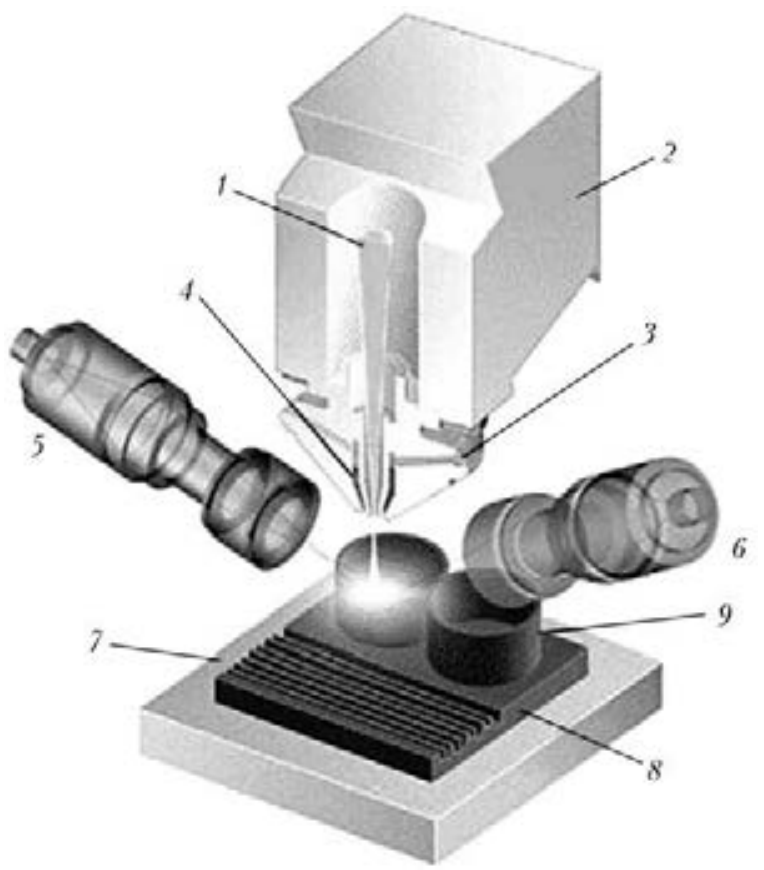

Figure 3. Schematic of process of 3D synthesis of parts by DMD technology: 1 - laser radiation; 2 - focusing optics; 3 - powder feeder; 4 - shielding gas; 5, 6 - sensors of feedback optical system; 7 - platform; 8 - blank (mould); 9 - created object pressure of ambient gas makes it attractive for application in plasma-chemical technologies (including CVD). Theoretical and experimental investigations conducted at PWI (Profs I.V. Krivtsun, V.S. Gvozdetsky, Yu.S. Borisov et al.) showed that such a discharge can form the basis for designing a new class of plasma devices integrated laser-arc plasmatrons.

Both direct- and indirect action plasmatrons can be applied in the processes of hybrid laserplasma surfacing [11-12]. Powders are mainly used as surfacing materials. The main advantage of application of direct-action plasmatrons is the possibility of additional compression of the plasma arc through application of focused laser radiation (Figure $2, a$ ). The advantage of application of indirect-action plasmatrons is absence of direct impact of electric arc on the base metal that, in particular, improves the thermal locality of the process (Figure 2, b) [13]. In the opinion of the authors of [14] application of pulsed radiation of Nd:YAG lasers is the most promising for this purpose, owing to the possibility of its flexible feeding through optical fibre in an optimized position in space. Laser-plasma surfacing considerably decreases residual stresses in the deposited layers, compared to laser surfacing. However, a considerable thermal impact on the item being surfaced remains to be one of its main disadvantages.

Analysis of the advantages and disadvantages of plasma, laser and laser-plasma surfacing processes suggests the following. In the case of plasma surfacing, the part can be exposed to considerable heating, leading to its residual thermal deformations. Laser and laser-plasma processes allow minimizing the part heating, improving the strength of adhesion of the deposited layers to the substrate, eliminating application of under- 
layers, and simplifying surface preparation. However, laser surfacing processes also have certain disadvantages. These include the stressed state of the deposited layers, presence of pores and microcracks in them. Hybrid (combined) laser-plasma processes allow partially or completely eliminating the above drawbacks, owing to interaction of the components or their simultaneous impact on the treated item. So, compression and stabilization of the plasma arc by laser radiation allows increasing the surfacing process speed and reducing the overall heat input; powder preheating by combined discharge in combination with variation of laser treatment thermal cycle due to addition of the plasma component, allows reducing residual stresses, eliminating pore and crack formation, etc.

Hybrid technologies of laser surfacing and coating have already found their practical application [15, 16]. For instance, developed technology of laser-plasma cementation of loom racks from steel 45 with base hardness $H R C$ 30-32 ensures surface layer hardness $H V 750$ as a result of treatment [15]. The process of surface layer carburizing is based not on diffusion, but on carbon adsorption by the surface and its convective stirring in the melt liquid phase that significantly increases the rate of conducting the technological process of cementation.

Thus, review of the processes of laser and hybrid (combined) surfacing showed that the following main tendencies of development of this area include: producing corrosion- and wear-resistant coatings with improved physico-mechanical characteristics; synthesis of 3D objects and development of thin coatings with special properties. Prospects for further development of laser and laser-plasma (laser-arc) surfacing processes are associated with the ability to eliminate the drawbacks inherent in each of the components taken separately through interaction of these components.

1. Grigoriants, A.G., Safonov, A.N. (1987) Laser engi neering and technology: Manual for higher education institutions. Vol. 3: Methods of surface laser treat- ment. Ed. by A.G. Grigoriants. Moscow: Vyschaya Shkola.

2. Velichko, O.A., Avramchenko, P.F., Molchan, I.V. et al. (1990) Laser powder cladding of cylindrical parts. Avtomatich. Svarka, 1, 59-65.

3. (2007) Laserstrahlschweissen mit pulverfoermigem Schweisszusatz. Edelstahl-Mechanik GmbH. Praktiker, 3, 68-69.

4. Zeng Xaoyan, Zhu Beidi, Tao Zengyi et al. (1993) Automatic powder feeder and technology of laser cladding. Chin. J. Lasers, 20(3), 210-214.

5. Pokhmurska, G.V. (2003) Crack formation in thermal coatings depending on laser remelting conditions. Fizyko-Khimichna Mekhanika Materialiv, 1, 59-62.

6. Chekurin, V.F., Pokhmurska, G.V. (2004) Mathematical model of cracking of laser-modified metal powder coatings. Ibid., 5, 18-22.

7. Hoffman, J. (2001) Reconditioning of exchangeable parts using laser technologies. The Paton Welding J., 12, 33-34.

8. Konyushin, A., Manyak, V., Holz, R. et al. (2009) Technical capabilities of modern solid-state lasers. Fotonika, 2, 22-23.

9. Birger, E.M., Moskvitin, G.V., Polyakov, A.N. et al. (2009) Industrial laser surfacing: State-of-the-art and tendencies. Svarochn. Proizvodstvo, 9, 3-8.

10. Gvozdetsky, V.S., Krivtsun, I.V., Chizhenko, M.I. et al. (1995) Laser-arc discharge: Theory and applications. In: Welding and Surfacing Rev., Vol. 3. Amsterdam: Harwood Acad. Publ.

11. Hai-ou Zhang, Ying-ping Qian, Gui-lan Wang (2006) Study of rapid and direct thick coating deposition by hybrid plasma-laser manufacturing. Surface \& Coatings Technology, 201, 1739-1744.

12. Chashchin, E.A., Fedin, A.V., Mitrofanov, A.A. et al. (2007) Increase of the efficiency of plasma treatment of materials at using of additional power source as laser radiation. In: Proc. of 3 rd Int. Sci.-Pract. Conf. on Study, Development and Application of High Technologies in Industry (14-17 March 2007, St.-Petersburg, Russia), Vol. 8: High technologies, fundamental and applied researche, 119-120. SPb: SPbPU.

13. Shelyagin, V.D., Khaskin, V.Yu., Pereverzev, Yu.N. (2006) Laser-microplasma alloying and coating of steel. The Paton Welding J., 2, 2-5.

14. Wilden, J., Bergman, J.P., Dolles, M. (2005) Riporti superficiali laser: aumento di efficienza e flessibilita tramite processi ibridi. Riv. Ital. Saldatura, 6, 809-816.

15. Zabelin, A.M., Shiganov, I.N. Chirkov, A.M. et al. (2007) Hybrid technologies of laser surfacing: Turorial. Moscow: MGOU.

16. Melyukov, V.V., Chirkov, A.M. (2006) Laser-plasma technologies for surface treatment. In: Proc. of 5 th Int. Conf. on Beam Technologies. Laser Application (23-28 Sept., 2006, St.-Petersburg, Russia), 236240

Received 08.04.2015 